\title{
Impact of Aligning Climatological Day on Gridding Daily Maximum-Minimum Temperature and Precipitation over Canada
}

\author{
Ron F. Hopkinson, ${ }^{*}$ Daniel W. McKenney, ${ }^{+}$Ewa J. Milewska, ${ }^{\#}$ Michael F. Hutchinson, ${ }^{@}$ \\ PiA PAPADOPOL ${ }^{+}$AND LUCIE A. VinCENT ${ }^{\#}$ \\ * Custom Climate Services, Inc., Regina, Saskatchewan, Canada \\ ${ }^{+}$Canadian Forest Service, Natural Resources Canada, Sault Ste. Marie, Ontario, Canada \\ \# Climate Research Division, Science and Technology Branch, Environment Canada, Toronto, Ontario, Canada \\ @ Australian National University, Canberra, Australian Capital Territory, Australia
}

(Manuscript received 20 October 2010, in final form 7 February 2011)

\begin{abstract}
On 1 July 1961, the climatological day was redefined to end at 0600 UTC at all principal climate stations in Canada. Prior to that, the climatological day at principal stations ended at 1200 UTC for maximum temperature and precipitation and 0000 UTC for minimum temperature and was similar to the climatological day at ordinary stations. Hutchinson et al. reported occasional larger-than-expected residuals at 50 withheld stations when the Australian National University Spline (ANUSPLIN) interpolation scheme was applied to daily data for 1961-2003, and it was suggested that these larger residuals were in part due to the existence of different climatological days. In this study, daily minimum and maximum temperatures at principal stations were estimated using hourly temperatures for the same climatological day as local ordinary climate stations for the period 1953-2007. Daily precipitation was estimated at principal stations using synoptic precipitation data for the climatological day ending at 1200 UTC, which, for much of the country, was close to the time of the morning observation at ordinary climate stations. At withheld principal stations, the climatological-day adjustments led to the virtual elimination of large residuals in maximum and minimum temperature and a marked reduction in precipitation residuals. Across all 50 withheld stations the climatological day adjustments led to significant reductions, by around $12 \%$ for daily maximum temperature, $15 \%$ for daily minimum temperature, and $22 \%$ for precipitation, in the residuals reported by Hutchinson et al.
\end{abstract}

\section{Introduction}

In Canada, the network of climatological stations that observe daily maximum and minimum temperature and precipitation is dominated by ordinary climate stations that make observations once or twice per day at fixed times. Most ordinary climate stations make two observations per day at 0700 and 1700 local standard time (Table 1). The morning observation is the end of the climatological day for maximum temperature and precipitation, and the value recorded over the $24 \mathrm{~h}$ ending at 0700 local time is assigned to the previous calendar day. For minimum temperature, the coldest temperature for the previous $24 \mathrm{~h}$ ending at 1700 local time is

Corresponding author address: Ewa J. Milewska, Climate Research Division, Science and Technology Branch, Environment Canada, 4905 Dufferin St., Toronto ON M3H 5T4 Canada.

E-mail: ewa.milewska@ec.gc.ca assigned to the current calendar day according to the information contained in the Station Information System of Canadian Climate Data Archives. A clear advantage of these definitions, in particular for applications, is that the observed maximums and minimums generally have clear interpretations. At most ordinary climate stations, the observed maximums mostly occur during the afternoon of the preceding day and the observed minimums mostly occur during the early hours of the morning of the current day. The situation is complicated in practice by some stations that make their observation just once per day. Indeed, fixed observing times can vary slightly from station to station depending on the practical requirements of the volunteer or the cooperating agency reading the weather instruments.

Approximately 1 station in 10 across southern Canada is a principal climatological station at which weather is observed on a synoptic (every $6 \mathrm{~h}$ ), intermediate synoptic (every $3 \mathrm{~h}$ ), or hourly basis. Table 1 indicates that 
TABLE 1. Climatological day history at Canadian principal (Allsopp 2004) and ordinary climate stations for daily maximum (Tmax) and minimum (Tmin) temperature and precipitation $(\mathrm{P})$.

\begin{tabular}{|c|c|c|c|c|}
\hline & \multicolumn{2}{|c|}{ Principal stations } & \multicolumn{2}{|c|}{ Ordinary stations } \\
\hline & Tmax; P & Tmin & Tmax; P & Tmin \\
\hline $1930 \mathrm{~s}$ & $0630 \mathrm{LST}$ & $1830 \mathrm{LST}$ & $0700 \mathrm{LST}$ & $1700 \mathrm{LST}$ \\
\hline 1940s & $1230 \mathrm{UTC}^{\mathrm{a}}$ & $0030 \mathrm{UTC}^{\mathrm{b}}$ & $0700 \mathrm{LST}$ & $1700 \mathrm{LST}$ \\
\hline May 1957 & $1200 \mathrm{UTC}^{\mathrm{c}}$ & $0000 \mathrm{UTC}^{\mathrm{d}}$ & $0700 \mathrm{LST}$ & $1700 \mathrm{LST}$ \\
\hline 1 Jul 1961 & 0600 UTC $^{\mathrm{e}}$ & 0600 UTC $^{\mathrm{e}}$ & 0700 LST & $1700 \mathrm{LST}$ \\
\hline
\end{tabular}

${ }^{\text {a }}$ Equivalent to 0730 eastern standard time.

${ }^{\mathrm{b}}$ Equivalent to 1930 eastern standard time.

${ }^{\mathrm{c}}$ Equivalent to 0700 eastern standard time.

d Equivalent to 1900 eastern standard time.

${ }^{\mathrm{e}}$ Equivalent to 0100 eastern standard time.

the climatological days for daily maximum and minimum temperature and precipitation at principal and ordinary climate stations were similar until 1 July 1961 at which date the climatological day at principal stations was changed to 0600 UTC (equivalent to local midnight in central standard time). The change was made to have the climatological day identified more closely with the calendar day because it was easier for the public to understand (M. K. Thomas 1984, personal communication). The interpretation of minimums observed at 0600 UTC is actually more complicated, however, because the time of the minimum can be close to this observation time. This makes it unclear in general whether the observed minimum occurs close to the beginning or the end of the 0600 UTC day.

The existence of disparate climatological days was identified by Hutchinson et al. (2009) as a possible source of the occasional larger residuals in the daily models generated by the Australian National University Spline (ANUSPLIN), which are the thin-plate smoothing spline-based climate interpolation algorithms of Hutchinson $(1995,2010)$. This has not been a significant issue for the gridding of monthly, annual, or 30-yr normals of temperature or precipitation for which differences in the climatological day are averaged over many days. Vincent et al. (2009) have also demonstrated that the difference in climatological day can produce a bias from $-0.2^{\circ} \mathrm{C}$ in the west to $-0.8^{\circ} \mathrm{C}$ in the east in the annual mean of the daily minimum temperature. This influence was more apparent in eastern Canada where, as noted above, 0600 UTC is close to the time at which the actual minimum temperature occurs. As a consequence, stations in eastern Canada were more likely to record the same (or a similar) minimum temperature on two successive days, creating a cold bias in the annual and monthly mean of the daily minimum temperature. This bias was significant with respect to the analysis of temporal trends in minimum temperature in eastern Canada.

Hutchinson et al. (2009) generated daily maximum and minimum temperature and precipitation models for the years from 1961 to 2003 . The station data were for the most part utilized as recorded in the Canadian Climate Data Archives. When the ANUSPLIN-derived values were evaluated against withheld station data, it was found that there were occasional large residuals between observed and estimated values and that many of these large residuals were associated with Canada's best climate stations: its principal stations. Maximum and minimum temperature residuals exceeding $4^{\circ} \mathrm{C}$ were uncomfortably common, but some residuals exceeded $20^{\circ} \mathrm{C}$. These very large residuals were usually associated with abnormal diurnal temperature patterns such as the temperature increasing at night or falling during the daytime hours. These were most common in the winter months but occasionally occurred even in the height of summer. In a similar way, occasional large residuals in precipitation were observed at principal stations. Careful inspection of the data revealed that most of these residuals could be explained by differences in the climatological day between the principal stations and the surrounding ordinary climate stations. A few of the large residuals were identified as data errors in the archive. It was more difficult to identify errors in daily precipitation because of the high spatial and temporal variability in this climate element.

The realization that differences in climatological day could be significant when producing gridded daily values led to the recalculation of these climate elements at principal stations for a climatological day matching that of the majority of the surrounding ordinary climate stations. An important aspect of the countrywide interpolations analyzed here is the consistency of the supporting data across the different time zones. As noted above, the local maximum and minimum temperatures do not generally occur near the end of their respective ordinary climate days. This means that both the temperature data and the interpolated temperature surfaces, if they are based on the standard ordinary climate days, generally have clear spatially continuous interpretations as the maximum of the preceding daytime and the minimum of the preceding night. In these terms, the adjusted precipitation data do suffer from minor spatial discontinuities as time zones are incremented in whole hours from east to west across Canada. This appears to be of little consequence in view of the complex spatial and temporal variability of precipitation. This paper describes the difference in climatological day between ordinary and principal stations in Canada, how these climate elements were adjusted to their respective 
TABLE 2. Observing time at ordinary and principal stations starting on $1 \mathrm{Jul} 1961$ for maximum and minimum temperature and precipitation, and for the different time zones in Canada.

\begin{tabular}{|c|c|c|c|c|c|c|}
\hline \multirow[b]{2}{*}{ Time zone } & \multicolumn{3}{|c|}{ Max temperature and precipitation } & \multicolumn{3}{|c|}{ Min temperature } \\
\hline & $\begin{array}{c}\text { Ordinary station } \\
\text { (LST) }\end{array}$ & $\begin{array}{c}\text { Principal station } \\
\left(\mathrm{LST}^{*}\right)\end{array}$ & Diff $(h)$ & $\begin{array}{c}\text { Ordinary station } \\
\text { (LST) }\end{array}$ & $\begin{array}{c}\text { Principal station } \\
\left(\mathrm{LST}^{*}\right)\end{array}$ & Diff $(h)$ \\
\hline Newfoundland & 0700 & 0230 & -4.5 & 1700 & 0230 & 9.5 \\
\hline Atlantic & 0700 & 0200 & -5 & 1700 & 0200 & 9 \\
\hline Eastern & 0700 & 0100 & -6 & 1700 & 0100 & 8 \\
\hline Central & 0700 & 0000 & -7 & 1700 & 0000 & 7 \\
\hline Mountain & 0700 & -0100 & -8 & 1700 & -0100 & 6 \\
\hline Pacific & 0700 & -0200 & -9 & 1700 & -0200 & 5 \\
\hline Yukon & 0700 & -0300 & -10 & 1700 & -0300 & 4 \\
\hline
\end{tabular}

* Times equivalent to 0600 UTC.

common climatological days, and the resulting significant reduction in the spatial model errors as measured by residuals at withheld stations.

\section{Data and procedures}

\section{a. Data}

The climate-day adjustment procedures used hourly observations for temperature and synoptic observations for precipitation. Hourly values of temperature were directly retrieved from the Canadian Climate Data Archive of Environment Canada for the period of 19532007. Hourly observations first began at airports in the 1940s and early 1950s but have been archived in digital form from 1953. Synoptic observations of precipitation were also retrieved from the archive and were available at principal stations for the whole period of 1950-2007. A fresh copy of the archived daily observations of maximum and minimum temperature and precipitation for the period from 1950 to 2007 was obtained before commencing this study because there are occasional corrections to daily data that have been found to be in error by users. One of the most common archive errors is a missing minus sign that had not been identified by the qualitycontrol procedures.

Also, because the observing time is based on UTC at principal stations, the temperature is observed at different local times across the country. Prior to 1 July 1961, the difference in climatological day between the principal and ordinary stations for maximum temperature was $0-1 \mathrm{~h}$ in central and eastern Canada and increased to about $2 \mathrm{~h}$ toward the eastern and western extremities of the country. For minimum temperature the difference between the two types of stations was about $1-2 \mathrm{~h}$ in central and western Canada and about 3-4 h in eastern Canada. These differences are relatively modest in comparison with the situation after 30 June 1961 when all principal stations had their climate days ending at
0600 UTC as shown in Table 2. For maximum temperature and precipitation the differences were greatest in the west, reaching $10 \mathrm{~h}$ in the Yukon until 1975 when the Yukon adopted the same time zone as British Columbia (Pacific); for minimum temperature the differences were the greatest in the east,being as much as $9.5 \mathrm{~h}$ in Newfoundland.

\section{b. Adjusting principal station data to a common climate day}

\section{1) Adjustments Before 1 July 1961}

Although the effect was modest before 1 July 1961, it was still possible to detect some climate-day differences between principal and ordinary stations for 1953-61. The principal station daily maximum and minimum temperatures for this period were estimated by using the highest and lowest hourly values for the $24 \mathrm{~h}$ ending at the observing time corresponding to the ordinary climate stations. The daily maximum and minimum temperatures represent the highest and lowest values over a 24-h period of continuous temperature and do not necessarily correspond to the highest and lowest values of the observations taken at the hourly intervals. To account for this, a small monthly correction, varying from $0.2^{\circ}$ to $0.6^{\circ} \mathrm{C}$, was added to the highest hourly values based on the average difference between the maximum temperatures from continuous observations and those computed from hourly observations for the same $24 \mathrm{~h}$ over the period from 1953 to June 1961. In a similar way, the minimum temperature for ordinary climate day was estimated from the lowest hourly temperature and similar small corrections were subtracted from these lowest hourly values based on the differences averaged over the same period under consideration. These small corrections were based on values computed for each principal station and were similar in magnitude to those identified after 30 June 1961 but varied slightly from station to station. No climate-day adjustment was 
possible for the 1950-52 data because no hourly values were archived for those years.

The programs used to adjust the maximum and minimum temperature to the same climate day as the surrounding ordinary climate stations also performed error checks between the hourly and daily data and identified probable errors in the archived daily temperature minima and maxima and in the hourly temperature archives. The suspect hourly errors were suppressed before the climate-day minima and maxima were calculated. It was beyond the scope of this study to investigate all of the suspect values, and therefore the simplest approach was not to use the suspect values in the estimation of the daily maximum or minimum temperature. If more than two hourly values were missing in a $24-\mathrm{h}$ period, the temperature maximum or minimum adjusted for climate day was set to missing. Because the climate day for precipitation ended at 1200 UTC already and the synoptic observation of precipitation is the finest resolution available in Canada, no climate-day adjustments to precipitation were required for dates that are before 1 July 1961.

\section{2) Adjustments After 30 June 1961}

A similar procedure was used to adjust the maximum and minimum temperature for climate day for dates that are after 30 June 1961, for which period daily values for the climatological day ending at 0600 UTC were replaced at principal stations by the values computed from hourly observations for the same 24 -h period as defined at nearby ordinary stations. The approach differs from Vincent et al. (2009) in four ways: 1) adjustment to the precise climate day of local ordinary climate stations, 2) adjustment to both maximum and minimum temperature, 3) computation of new minimum and maximum temperatures for all days, and 4) use of a variable monthly correction factor.

Not all daily values were changed after the application of the climate-day adjustment. For maximum temperature, $10 \%-15 \%$ of the values at principal stations with 24-h observing programs were changed by the climateday adjustment; for minimum temperature, $47 \%$ of the values were changed in the east and $17 \%$ in the west for the period of 1961-2007. Thus, the climate-day adjustment had a more frequent impact on minimum temperature than on maximum temperature and that impact was greatest in eastern Canada. For illustration, the 50th and 90th percentiles of the absolute values of the climate-day adjustments of maximum or minimum temperature were, respectively, less than $1.0^{\circ}$ and $2.5^{\circ} \mathrm{C}$ at Victoria, British Columbia, on the west coast $1.3^{\circ}$ and $4.2^{\circ} \mathrm{C}$ at Gander, Newfoundland, on the east coast; and $1.8^{\circ}$ and $5.7^{\circ} \mathrm{C}$ at Regina, Saskatchewan, in central Canada. The Regina distribution was representative of continental stations from the prairies to Ontario. Victoria's distribution was unique and was attributed to the strong moderating influence of its maritime climate in the winter months. The moderating effect of the ocean on Gander was less pronounced and the time-zone effect dominated in the east. The greatest climate-day adjustments were as high as $15^{\circ}-20^{\circ} \mathrm{C}$ and were associated with abnormal diurnal temperature patterns as noted earlier.

As with climate-day adjustments before July of 1961, representative monthly corrections were estimated from a sample of principal stations by averaging the differences between the actual maximum (minimum) daily temperatures and the highest (lowest) hourly values for the principal station climate day for 1961-2007. These corrections were similar in magnitude to those before July of 1961 and ranged from $0.2^{\circ} \mathrm{C}$ in winter to $0.6^{\circ} \mathrm{C}$ in summer months for maximum temperature and from $-0.3^{\circ} \mathrm{C}$ in summer to $-0.4^{\circ} \mathrm{C}$ in the remaining months of the year for minimum temperature.

Although some hourly precipitation data exist for Canada, they are mainly for rainfall and are not recorded at all principal stations. Nevertheless, synoptic precipitation (rain plus snow water equivalent) was available for almost all principal stations and could be used after 30 June 1961 to adjust for a climate day closest to that of the ordinary climate stations (early morning to early morning). The 6-h synoptic precipitation values were used to calculate the 24-h total ending at 1200 UTC versus 0600 UTC and to assign the resultant value to the previous calendar day. In this case, no missing synoptic value was permitted and therefore a missing synoptic value meant that the adjusted daily total was also missing. The climate days for precipitation were still not exactly coincident in most parts of Canada even after adjustment for climate day because 1200 UTC matches 0700 LST only in the eastern time zone-Ontario and Quebec.

More principal stations could not be adjusted for climate-day redefinition in the case of temperature than in the case of precipitation. For the temperature climate-day adjustment, about $50 \%$ of the principal stations in Canada had full 24-h observing programs until the 1980s. With the introduction of automatic stations, this improved to over $70 \%$ in the 1990 s. North of $54^{\circ} \mathrm{N}$, only one-third of principal stations had $24-\mathrm{h}$ observing programs, which increased to over $60 \%$ in the 1990s. For precipitation climate-day adjustment, virtually all synoptic stations had four synoptic observations per day and therefore there were only a few principal stations that could not be processed.

The new adjusted temperature and precipitation values were then merged into the daily datasets. This ultimately meant retaining the ordinary climate stations as they were but substituting the adjusted climate-day values at 
the principal stations when a valid value was able to be calculated. If a climate-day-adjusted value was not available because the requisite hourly data were missing, then the unadjusted archive value was retained. There was some additional processing to the precipitation to account for trace and accumulation flags as described in Hutchinson et al. (2009). Data files were then formatted for direct input to ANUSPLIN.

\section{c. Evaluating the impact on the ANUSPLIN models}

The ANUSPLIN models based on the unadjusted data (Hutchinson et al. 2009) were obtained by fitting thin-plate smoothing splines that incorporated a spatially and temporally varying dependence on ground elevation. In keeping with other studies and the nature of precipitation data, daily precipitation was interpolated in a two-stage process that separately interpolated positive precipitation values and precipitation occurrence. Errors based on withheld data across southern Canada were comparable to, or smaller than, errors obtained by daily interpolation studies elsewhere with denser data networks. In particular, mean absolute errors in daily maximum and minimum temperature for the 50 withheld data points averaged over 1965, 1975, and 1985 were just $1.1^{\circ}$ and $1.6^{\circ} \mathrm{C}$, respectively (Hutchinson et al. 2009). These analyses were augmented for this study by analyses based on the unadjusted data for 1955, 1995, and 2005.

The same thin-plate smoothing spline approach was applied to the same data network with data values adjusted to a common climate day. Withheld data assessments were applied for 1955, 1965, 1975, 1985, 1995, and 2005 to daily maximum temperature, daily minimum temperature, and daily precipitation.

The same 50 stations were withheld for unadjusted and adjusted studies and are shown by station type in Fig. 1. As described in Hutchinson et al. (2009), the withheld stations were chosen from Canada's Reference Climate Station network to equisample three-dimensional longitude, latitude, and elevation space and to provide stations of high quality with long records. The station selection was restricted to southern Canada where the network density was much higher and where there was a mixture of ordinary and principal climate stations.

Eleven of the 50 withheld stations were classified as ordinary climate stations. For temperature, 35 of the withheld stations were principal stations with full 24-h weather observing programs. Four other principal stations were designated as synoptic stations because they were first-order stations that did not have a 24-h weather observing program but had synoptic observations including 0600 UTC. These synoptic stations had a climate day ending at 0600 UTC after 30 June 1961, the same as the principal stations. The method of adjusting temperature to the same climate day as the ordinary climate stations could not be applied to the stations that lacked a 24-h observing program, however. For precipitation, these four stations had a full synoptic program and therefore it was possible to adjust precipitation for climate day in the same fashion as at the principal stations. Thus there were 39 principal stations for the withheld precipitation tests.

Approximately 2000 temperature stations and over 2700 precipitation stations remained in the data pool to develop the daily ANUSPLIN surfaces for each of the three climatological elements. Estimates of the value of the climate element at the location of each withheld station were compared with the observed (recorded) values. Mean error (ME), standard deviation (SD), and mean absolute error (MAE) statistics between the estimated and observed values from unadjusted and adjusted climate-day studies were examined.

\section{Results}

\section{a. Impact on maximum temperature at withheld stations}

The differences between the model and observed data were plotted before and after adjustment and reviewed in detail for all 50 stations. Figure 2 illustrates comparative plots for Winnipeg International Airport in Manitoba. Larger daily differences were apparent mainly in the winter months for the unadjusted data (Fig. 2a). These were attributed primarily to the difference in climatological day between this principal station and the surrounding ordinary climate stations. The improvement in the agreement between the model estimates and the adjusted values for maximum temperature at Winnipeg was substantial (Fig. 2b). This comparison is typical of the impact at all 35 withheld principal stations as summarized in Table 3 for the year 1975. The statistical response at individual stations was noted by graphing the change in ME, MAE, and SD by station (not shown). With the exception of Daniel's Harbour, Newfoundland, all principal stations showed a decrease in the standard deviation of the estimated versus observed value for maximum temperature after the adjustment to a common climate day.

In contrast to the principal stations, there were only minor changes in ME, MAE, and SD values at the synoptic and ordinary climate stations (Table 3 ). In the case of the four synoptic stations, there were numerous large daily differences in the unadjusted data study that appeared to be due to the differences in climate day from nearby ordinary climate stations. These remained in the adjusted 


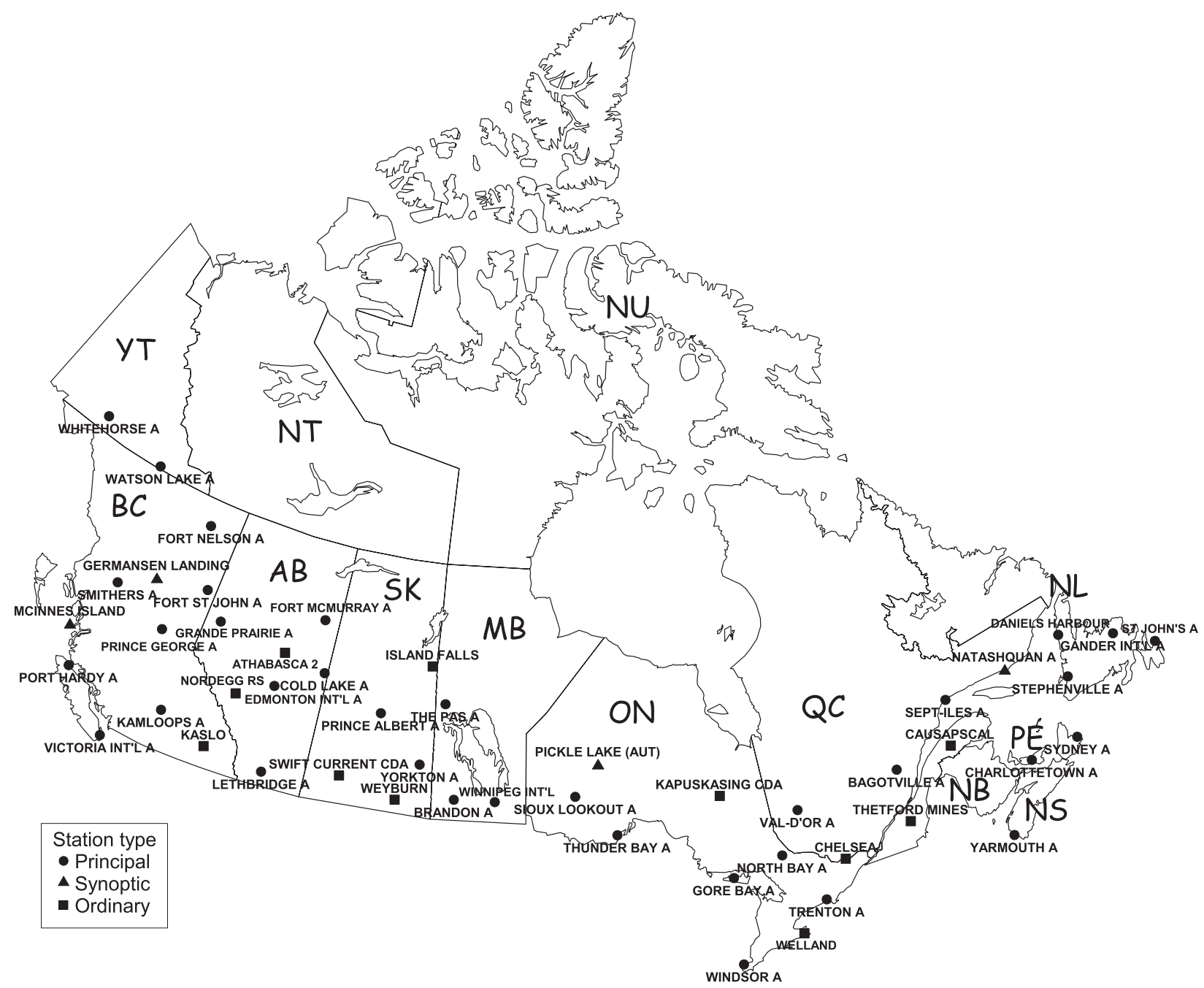

FIG. 1. Location and type of withheld stations.

data study because there was no objective way to adjust the daily temperature values appropriately.

Most of the 11 ordinary climate stations displayed very little change in either SD or MAE except for improvement in statistics for Swift Current, Saskatchewan, Canada Department of Agriculture (CDA) station and Kapuskasing, Ontario, CDA (Table 3). The former is very close to the principal station Swift Current A, and the implied improvement to the Swift Current A statistics due to climate-day adjustment was probably reflected in improved difference statistics at Swift Current CDA. The Kapuskasing CDA station is relatively remote in northern Ontario, where most of the stations are principal stations, which similarly would have reduced climate-day type differences, leading to better predictions at the ordinary climate station at Kapuskasing CDA. Last, SD and MAE of the differences at principal stations after adjustment approached those at the ordinary climate stations, suggesting that both principal and ordinary stations were more homogeneous spatially after the climate-day adjustment.

Similar results were observed in all withheld years except for 1955, which required fewer and smaller climateday adjustments, because the climatological days were similar at the principal and ordinary stations before 1961. The summary statistics for all withheld stations and all tested years are presented in Table 4: it shows that the mean error has slightly increased for 1965 , 1975 and 1985. Most of the improvement in SD and MAE is associated with the principal stations. There appears to be a slight declining trend in the SD and MAE for all withheld stations from 1955 to 2005, possibly because of an initial increase in the number of climate stations and, since 1990, the better spatial distribution of stations with the introduction of many automatic stations. 

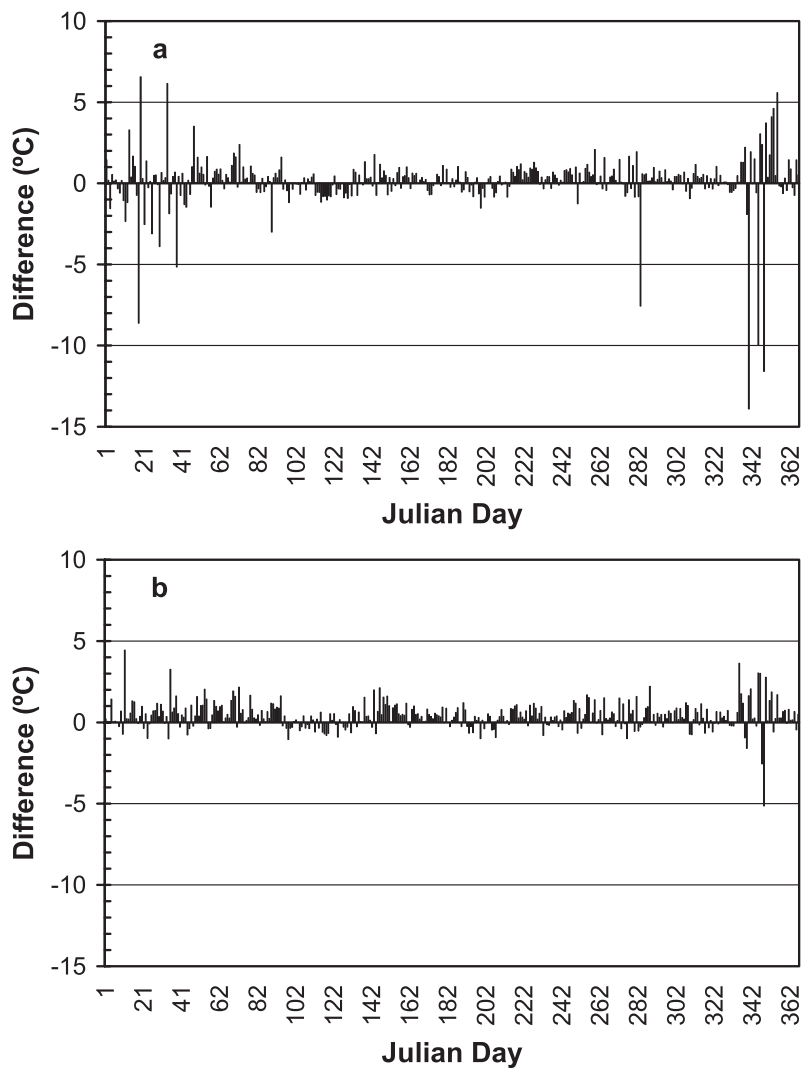

FIG. 2. Daily differences at Winnipeg International Airport in 1975 between the ANUSPLIN estimates and the observed values of maximum temperature (a) before adjustment for climate day and (b) after adjustment for climate day.

\section{b. Impact on minimum temperature at withheld stations}

Figure 3 depicts the daily minimum temperature before and after adjustment to the climate day at Gander International Airport in 1975. Similar to the impact of adjusted maximum temperature, the differences between model estimates and observations have decreased as a result of adjusting for the climate day. Before adjustment, there were numerous large positive differences whereas after adjustment virtually all of the positive differences have been eliminated. It is evident in this case, however, that estimates from the model are colder than those of the principal station minimum adjusted for the climate day ending in the late afternoon. These small negative differences vary mostly between $-0.5^{\circ}$ and $-1.0^{\circ} \mathrm{C}$. At a couple of stations, including Edmonton International Airport in Alberta, the small differences were positive, but that may be caused by the nearby heat island effect known to occur at Edmonton City Centre station. The change in ME, MAE, and SD appears to be greater in eastern Canada, probably because these stations were more frequently affected by the redefinition of climatological day for minimum temperature (Vincent et al. 2009). Except for Swift Current CDA and Kapuskasing CDA, the changes in the difference statistics at ordinary climate stations were slight. Table 3 shows the statistics before and after the adjustment for each type of climate station in 1975.

Table 5 displays the minimum temperature statistics for all withheld stations for every tenth year from 1955 to 2005. There was an improvement in all years for which there were comparable data. Virtually all of the improvement was associated with the principal stations on the basis of a detailed analysis of different station types. Both the SD and MAE were larger for minimum temperature than for maximum temperature because minimum temperature is more highly variable spatially. For 1955, there was no significant change in the difference statistics because the difference in climate day was small before 1961. Over the 40 years from 1965 to 2005, there was a consistent decrease in both the SD and MAE of the differences. The Canadian climate network of temperature stations peaked in density from the mid-1970s to the mid-1990s. This may explain some of the initial improvement but not the continued decrease in the difference statistics in 2005. There has been considerable network rationalization commencing in the mid1990s, which may have reduced the number of ordinary climate stations with once-per-day observing programs and nonstandard observing times. Another major change in the network since the early 1990s was the shift to automation at principal stations and a significant increase in secondary automated stations across Canada. It is not clear whether these changes or other influences have been responsible for the recent improvement in the agreement between the estimates of minimum temperature and the measured/recorded values at the withheld stations.

After large mostly positive differences for minimum temperature and large mostly negative differences for maximum temperature were eliminated with the adjustment of climatological-day definition (Figs. 2b, 3b), the remaining differences resulted in a more negative ME for minimum temperature or more positive ME for maximum temperature (Table 3). The ME appears to be very sensitive to the choice of correction factor and could be reduced by using a slightly larger correction factor in most parts of the country. Site-specific correction factors also have the potential to improve the ME slightly. Other possible sources of increased ME could include differences in instruments and precision between ordinary and principal stations, although investigations thus far do not support this hypothesis. Also, most principal stations are airports located near urban areas and 
TABLE 3. The ME, MAE, and SD calculated from the differences between model data and station maximum and minimum temperature data $\left({ }^{\circ} \mathrm{C}\right)$, for the three types of withheld stations, before and after adjustment for the climate day, in 1975 . Results are averaged for 365 days.

\begin{tabular}{|c|c|c|c|c|c|}
\hline \multirow[b]{2}{*}{ Type } & & \multicolumn{2}{|c|}{ Max temperature $\left({ }^{\circ} \mathrm{C}\right)$} & \multicolumn{2}{|c|}{ Min temperature $\left({ }^{\circ} \mathrm{C}\right)$} \\
\hline & & $\begin{array}{c}\text { Before } \\
\text { adjustment }\end{array}$ & $\begin{array}{c}\text { After } \\
\text { adjustment }\end{array}$ & $\begin{array}{c}\text { Before } \\
\text { adjustment }\end{array}$ & $\begin{array}{c}\text { After } \\
\text { adjustment }\end{array}$ \\
\hline \multicolumn{6}{|l|}{ Principal stations (35) } \\
\hline & ME & 0.09 & 0.34 & 0.03 & -0.58 \\
\hline & MAE & 1.13 & 0.99 & 1.55 & 1.26 \\
\hline & SD & 1.66 & 1.24 & 2.06 & 1.49 \\
\hline \multicolumn{6}{|l|}{ Ordinary stations (11) } \\
\hline \multirow[t]{3}{*}{ Nine stations } & ME & 0.03 & 0.04 & 0.17 & 0.2 \\
\hline & MAE & 0.91 & 0.91 & 1.38 & 1.39 \\
\hline & SD & 1.24 & 1.22 & 1.75 & 1.75 \\
\hline \multirow[t]{3}{*}{ Two stations: Swift Current and Kapuskasing } & ME & 0.47 & 0.36 & -0.73 & -0.27 \\
\hline & MAE & 0.88 & 0.69 & 1.31 & 0.88 \\
\hline & $\mathrm{SD}$ & 1.25 & 0.85 & 1.73 & 1.12 \\
\hline \multicolumn{6}{|l|}{ Synoptic stations (4) } \\
\hline & $\mathrm{ME}$ & -0.14 & -0.12 & 0.17 & 0.21 \\
\hline & MAE & 1.39 & 1.39 & 1.85 & 1.88 \\
\hline & $\mathrm{SD}$ & 2.02 & 2.03 & 2.17 & 2.21 \\
\hline
\end{tabular}

therefore another possibility is that at some stations there could be real but subtle differences in climate between rural ordinary climate stations and principal airport stations; there is some evidence at some sites to support this as another cause of the increased ME at the withheld principal stations. Ongoing testing suggests that the retention of measured maximum and minimum temperature when a climate-day adjustment is not required will lead to a small improvement in the ME.

\section{c. Impact on daily precipitation at withheld stations}

The improvement in the difference statistics for maximum and minimum temperature was important and consistent across all years after 1955. The adjustment for climate day with respect to daily precipitation resulted in a surprisingly large improvement in the difference statistics at all withheld precipitation stations. The impact of adjusting the climate day at Victoria International Airport in Fig. 4b as compared with the unadjusted data in Fig. 4a illustrates this well, where all but 1 of the
18 differences that are larger than $10 \mathrm{~mm}$ have been removed or reduced. Smaller climate-day differences are still present in the Victoria record because there is a 3-h difference between 1200 UTC and 0700 LST in the Pacific time zone.

The impact of the change in climate day on the standard deviation, mean absolute error, and mean error of the differences at the principal stations was analyzed by station type. There was virtually no change in the ME, which was close to zero both before and after the adjustment of precipitation to a common climate day (Table 6). There was a significant improvement in SD of the differences at the 39 withheld principal stations from 3.38 to $2.41 \mathrm{~mm}$. Also, the average MAE for all days was reduced from 1.53 to $1.06 \mathrm{~mm}$ in 1975. The greatest reductions in MAE were at withheld principal stations with high annual precipitation on the east and west coasts. Although there was no change in the precipitation data at the ordinary climate stations, there was a modest improvement in the difference statistics at all but one of the withheld ordinary

TABLE 4. Summary of withheld data difference statistics for daily maximum temperature $\left({ }^{\circ} \mathrm{C}\right)$ for six withheld years before and after adjustment for climate day.

\begin{tabular}{|c|c|c|c|c|c|c|c|c|c|c|c|c|}
\hline & \multirow[b]{2}{*}{ No. of days* } & \multirow[b]{2}{*}{ No. of stations } & \multicolumn{2}{|c|}{$\mathrm{ME}$} & \multicolumn{2}{|c|}{ SD } & \multicolumn{2}{|c|}{ MAE } & \multicolumn{2}{|c|}{ Max negative diff } & \multicolumn{2}{|c|}{ Max positive diff } \\
\hline & & & Before & After & Before & After & Before & After & Before & After & Before & After \\
\hline 1955 & 16071 & 45 & 0.13 & 0.11 & 1.80 & 1.78 & 1.24 & 1.23 & -13.06 & -13.42 & 16.86 & 17.56 \\
\hline 1965 & 17756 & 49 & 0.00 & 0.21 & 1.84 & 1.52 & 1.18 & 1.01 & -19.21 & -16.46 & 16.64 & 14.57 \\
\hline 1975 & 18180 & 50 & 0.08 & 0.25 & 1.72 & 1.45 & 1.10 & 1.00 & -14.42 & -15.16 & 16.03 & 15.46 \\
\hline 1985 & 18094 & 50 & 0.11 & 0.26 & 1.76 & 1.45 & 1.11 & 0.98 & -27.21 & -11.06 & 14.46 & 14.92 \\
\hline 1995 & 16556 & 47 & 0.32 & 0.35 & 1.63 & 1.39 & 1.07 & 0.95 & -18.86 & -8.65 & 15.00 & 14.91 \\
\hline 2005 & 15820 & 45 & 0.12 & 0.18 & 1.40 & 1.24 & 0.91 & 0.83 & -22.24 & -22.21 & 12.22 & 22.66 \\
\hline
\end{tabular}

* Total number of days before adjustment (the number of station days changes slightly after adjustment because of missing values). 

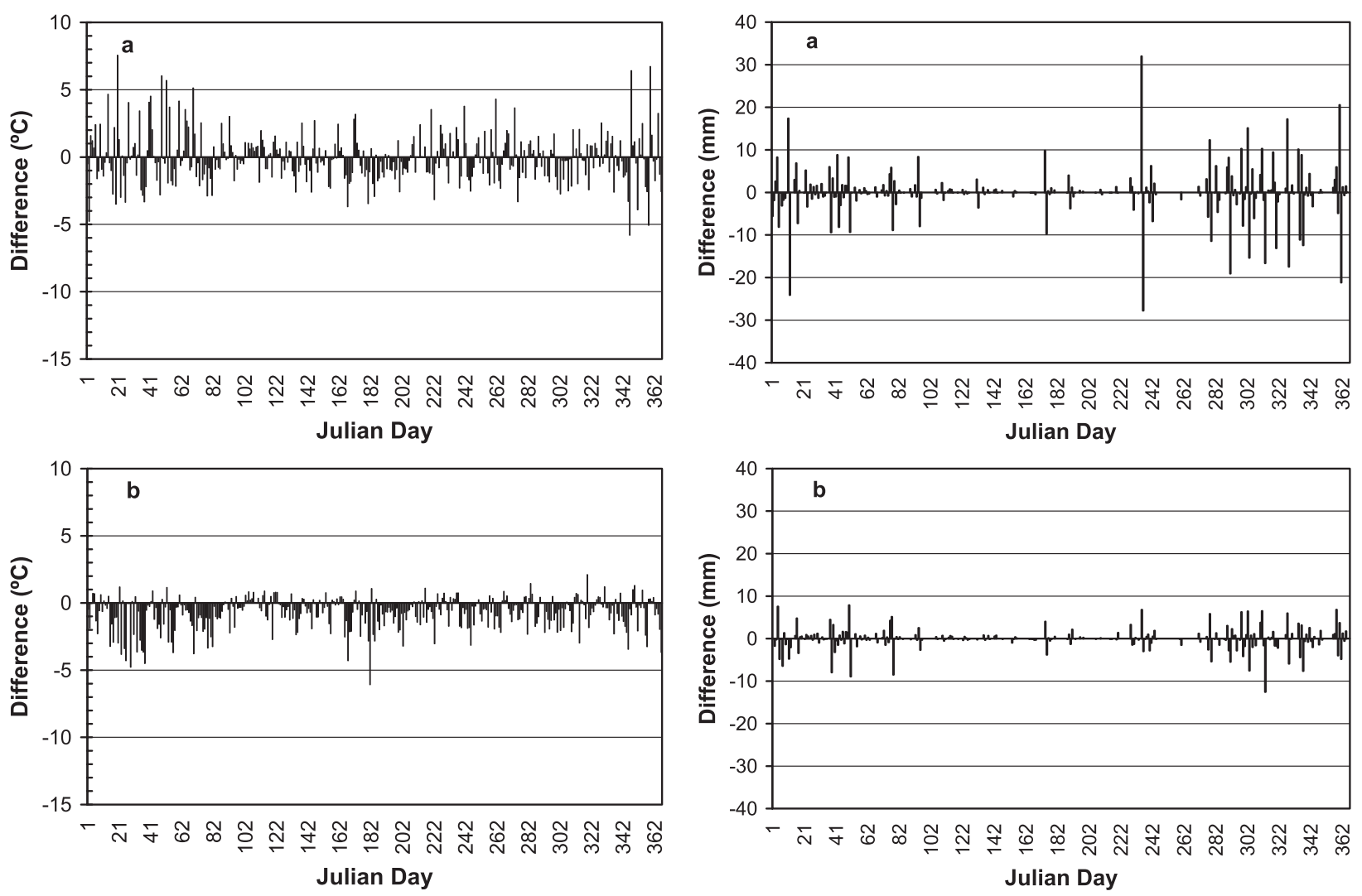

FIG. 3. Daily differences at Gander International Airport in 1975 between the ANUSPLIN estimates and the observed values of minimum temperature (a) before adjustment for climate day and (b) after adjustment for climate day.

climate stations. For 1975 the standard deviation of the differences at the 11 ordinary climate stations decreased from 2.27 to $2.09 \mathrm{~mm}$ (Table 6). This may reflect an overall improvement in the precipitation models attributable to the alignment of the climate day at the principal stations even though they compose just $10 \%$ of the network.

Table 7 summarizes the difference statistics for wetday precipitation for all withheld stations for the years that were tested. Here wet-day precipitation is defined

FIG. 4. Daily differences at Victoria International Airport in 1975 between the ANUSPLIN estimates and the observed values of daily precipitation (a) before adjustment for climate day and (b) after adjustment for climate day.

as those days with observed precipitation greater than $0.2 \mathrm{~mm}$. The improvement to the overall standard deviation and MAE of the differences is evident. The residual statistics decreased over time until about 1985 and then began to increase. The mid-1980s corresponded with the peak of the climate network density for daily precipitation. The decline in network density since the early 1990s has continued through the 2000s. Precipitation is highly variable in time and space such that

TABLE 5. Summary of withheld difference statistics for daily minimum temperature $\left({ }^{\circ} \mathrm{C}\right)$ for six withheld years before and after adjustment for climate day.

\begin{tabular}{|c|c|c|c|c|c|c|c|c|c|c|c|c|}
\hline & \multirow[b]{2}{*}{ No. of days* } & \multirow[b]{2}{*}{ No. of stations } & \multicolumn{2}{|c|}{ ME } & \multicolumn{2}{|c|}{ SD } & \multicolumn{2}{|c|}{ MAE } & \multicolumn{2}{|c|}{ Max negative diff } & \multicolumn{2}{|c|}{ Max positive diff } \\
\hline & & & Before & $\overline{\text { After }}$ & Before & $\overline{\text { After }}$ & Before & $\overline{\text { After }}$ & Before & After & Before & After \\
\hline 1955 & 15920 & 45 & -0.40 & -0.42 & 2.10 & 2.06 & 1.54 & 1.50 & -12.81 & -12.19 & 18.68 & 18.77 \\
\hline 1965 & 17725 & 49 & -0.04 & -0.37 & 2.25 & 1.87 & 1.60 & 1.35 & -14.44 & -14.14 & 16.07 & 13.99 \\
\hline 1975 & 18181 & 50 & 0.03 & -0.37 & 2.17 & 1.82 & 1.53 & 1.31 & -15.01 & -12.12 & 18.16 & 14.55 \\
\hline 1985 & 18093 & 50 & -0.06 & -0.42 & 2.29 & 1.89 & 1.62 & 1.36 & -25.39 & -13.31 & 20.30 & 20.74 \\
\hline 1995 & 16557 & 47 & 0.05 & -0.27 & 2.26 & 1.86 & 1.62 & 1.32 & -11.28 & -8.78 & 27.31 & 15.38 \\
\hline 2005 & 15820 & 45 & -0.02 & -0.29 & 1.90 & 1.63 & 1.36 & 1.13 & -15.75 & -15.92 & 12.16 & 11.56 \\
\hline
\end{tabular}

* Total number of days before adjustment (the number of station days changes slightly after adjustment because of missing values). 
TABLE 6. The ME, MAE, and SD calculated from the differences between model data and station precipitation data $(\mathrm{mm})$, for the two types of withheld stations, before and after adjustment for the climate day, in 1975. Results are averaged for 365 days.

\begin{tabular}{clcc}
\hline \hline & & \multicolumn{2}{c}{ Precipitation $(\mathrm{mm})$} \\
\cline { 3 - 4 } Type & & $\begin{array}{c}\text { Before } \\
\text { adjustment }\end{array}$ & $\begin{array}{c}\text { After } \\
\text { adjustment }\end{array}$ \\
\hline Principal stations (39) & ME & -0.02 & -0.02 \\
& MAE & 1.53 & 1.06 \\
Ordinary stations (11) & SD & 3.38 & 2.41 \\
& ME & -0.05 & -0.05 \\
& MAE & 0.89 & 0.83 \\
& SD & 2.27 & 2.09 \\
\hline
\end{tabular}

predictability falls off very quickly with distance. Thus a decrease in network density has given rise to an increase in the distance between stations and a general decrease in predictability at locations where precipitation is not measured. Another factor since the early 1990s has been the automation of precipitation measurements. This change has been much less successful than the automation of temperature measurements (Milewska and Hogg 2002). Automated systems do not measure trace amounts, do not discriminate between rain and snow, and have great difficulty measuring snowfall. In connection with automated snowfall measurements in Canada, there is in fact a variety of gauges in the network and there has been a movement away from Nipher shields to Alter shields. In the Canadian Climate Data Archive, no special processing has been done to adjust for catch efficiencies associated with the different gauges and shielding methods, and thus the data have been archived as recorded.

\section{d. Overall impact on the accuracy of the interpolated climate grids}

The average MAEs of the interpolated temperature and precipitation grids for the representative years 1965, 1975, and 1985 as obtained from Tables 4, 5, and 7 are listed in Table 8 for direct comparison with the summary error statistics presented in Table 8 of Hutchinson et al. (2009). The values in Table 8 show an overall $12 \%$ reduction in the MAE for maximum temperature from around $1.13^{\circ} \mathrm{C}$ to around $1.00^{\circ} \mathrm{C}$, a $15 \%$ reduction in the MAE for minimum temperature from around $1.58^{\circ} \mathrm{C}$ to around $1.34^{\circ} \mathrm{C}$, and a $22 \%$ reduction in the MAE for wet-day precipitation from around $2.79 \mathrm{~mm}$ to around $2.17 \mathrm{~mm}$. The temperature errors already compared well to the errors for the other methods cited in Hutchinson et al. (2009) that had been applied to much denser data networks than that of the southern half of Canada. With the use of the adjusted data the maximum and minimum temperature errors are now virtually the same as those obtained by the "Daymet" method as applied by Hasenauer et al. (2003) to a data network with 6 times the density. The precipitation errors are also now better than those cited by all of the other methods, with the sole exception of the analysis by Shen et al. (2001) for a dense data network with restricted elevation coverage.

Similar climate-day discrepancies are likely present in the United States and other national archives of daily climate data, and users should be aware that there could be large climate-day differences between station types on some days in either daily temperature or precipitation that will have an impact on spatial models.

The new Canada-wide daily temperature and precipitation gridded data that are based on climate-dayadjusted data are available for 1950-2007 upon request. The standard product is available at a resolution of 300 arc s, but point- and day-specific estimates and more customized grids may be available upon special request.

\section{Summary and conclusions}

To produce high-quality gridded climate fields of maximum and minimum temperature and precipitation on a daily basis, it is important to align station climate days as closely as possible. Analysts typically take weather/ climate station data quality for granted and develop

TABLE 7. Summary of withheld difference statistics for six withheld years for wet-day $(>0.2 \mathrm{~mm})$ precipitation ( $\mathrm{mm})$ before and after adjustment for climate day.

\begin{tabular}{|c|c|c|c|c|c|c|c|c|c|c|c|c|}
\hline & \multirow[b]{2}{*}{ No. of days* } & \multirow[b]{2}{*}{ No. of stations } & \multicolumn{2}{|c|}{ ME } & \multicolumn{2}{|c|}{$\mathrm{SD}$} & \multicolumn{2}{|c|}{ MAE } & \multicolumn{2}{|c|}{ Max positive diff } & \multicolumn{2}{|c|}{ Max negative diff } \\
\hline & & & Before & After & Before & After & Before & After & Before & After & Before & After \\
\hline 1955 & 6773 & 46 & -0.61 & -0.61 & 4.69 & 4.69 & 2.73 & 2.73 & -66.80 & -66.80 & 24.82 & 24.82 \\
\hline 1965 & 7564 & 50 & -0.63 & -0.46 & 4.92 & 4.13 & 2.86 & 2.30 & -39.24 & -50.87 & 40.55 & 37.19 \\
\hline 1975 & 7903 & 50 & -0.47 & -0.23 & 4.92 & 3.78 & 2.76 & 2.08 & -71.62 & -55.27 & 48.25 & 35.18 \\
\hline 1985 & 7113 & 50 & -0.53 & -0.27 & 5.00 & 3.89 & 2.76 & 2.13 & -75.22 & -66.46 & 34.50 & 29.00 \\
\hline 1995 & 6607 & 47 & -0.61 & -0.39 & 5.30 & 4.01 & 2.95 & 2.24 & -63.71 & -59.40 & 48.20 & 33.36 \\
\hline 2005 & 5967 & 45 & -0.49 & -0.38 & 5.45 & 4.29 & 3.04 & 2.28 & -83.73 & -96.97 & 36.20 & 26.72 \\
\hline
\end{tabular}

* Total number of wet days before adjustment (the number of station days changes slightly after adjustment because of missing values). 
TABLE 8. Mean absolute errors for 50 withheld stations before and after climate data adjustment for the representative years 1965,1975 , and 1985 as reported in Hutchinson et al. (2009). Sample sizes for temperature and wet-day precipitation, respectively, were 54030 and 22580 .

\begin{tabular}{lcccc}
\hline \hline & $\begin{array}{c}\text { MAE max } \\
\text { temperature }\left({ }^{\circ} \mathrm{C}\right)\end{array}$ & $\begin{array}{c}\text { MAE min } \\
\text { temperature }\left({ }^{\circ} \mathrm{C}\right)\end{array}$ & $\begin{array}{c}\text { MAE precipitation } \\
\text { (all days; mm) }\end{array}$ & $\begin{array}{c}\text { MAE precipitation } \\
(\text { wet days; mm) }\end{array}$ \\
\hline Before adjustment & 1.13 & 1.58 & 1.38 & 2.79 \\
After adjustment & 1 & 1.34 & 1.03 & 2.17 \\
\hline
\end{tabular}

spatial models with limited scrutiny. Here, hourly temperature data have been used to determine the daily maximum and minimum temperatures at principal stations for a climate day matching the bulk of the ordinary climate stations that dominated the network from 1955 to 2005. An added advantage of adopting the standard observation times of 0700 and 1700 LST for maximum and minimum temperatures, respectively, is that the observations have clear spatially continuous interpretations as the maximum of the preceding daytime and the minimum of the preceding night. This makes the observations well suited to countrywide interpolation, as investigated here. The method could not be applied to up to $50 \%$ of the principal stations that lacked a $24-\mathrm{h}$ observing program. These stations were not adjusted and remain problematic for daily spatial analysis. After 1961, archived synoptic precipitation (6 h) data were used to compute daily precipitation ending at 1200 UTC, the synoptic hour closest to the morning observation of precipitation at most ordinary climate stations across Canada. Precipitation was not adjusted before 1961 because the time of daily precipitation observation at principal stations was 1200 UTC already.

The impact of the change in climate day to 0600 UTC at principal climate stations on 1 July 1961 was significant for the spatial analysis of the daily climate fields. The adjustment of daily maximum and minimum temperature and precipitation to a climate day aligned with that of the bulk of the ordinary climate stations has resulted in improved estimates of all three climate elements at the withheld principal station locations. The overall reductions in error for the interpolated grids further attest to the quality of the underlying thin-plate smoothing method, as applied here. One interesting albeit unexpected result was that most of the differences remaining after the adjustments are negative in the case of minimum temperature and positive in the case of maximum temperature. Because of this, the temperature estimates at the withheld principal stations exhibited a small bias after adjustment for climate day. Several attempts to provide an adequate explanation for this phenomenon have yielded mixed results to date. Refinements to the climate-day adjustment procedure, such as retaining all measured values that did not require a climate-day adjustment and using site-specific correction factors, will be implemented for North American datasets currently under development and are expected to lead to modest reductions in mean error.

At the withheld ordinary climate stations, the impact of the climate-day adjustments at the principal stations was slight for temperature except at those locations that were strongly influenced by nearby climate-dayadjusted principal station values. The greatest relative improvement was for daily precipitation, and this was evident not only at the withheld principal stations but also to a modest extent at the withheld ordinary climate stations. This underlines the importance of data quality, as well as methodological quality, in satisfactorily analyzing the complex spatial patterns exhibited by daily precipitation. The new datasets developed here provide improved spatial estimates for a variety of applications that require daily maximum and minimum temperature and precipitation.

There remain other sources of uncertainty in the daily datasets. One is the existence of ordinary climate stations with once-per-day observations and ordinary stations with nonstandard observing times. It will require a significant effort to resolve this problem because of limited and incomplete documentation of such information over time. Another issue is the probable presence of errors in the temperature data in the Canadian Climate Data Archive at ordinary climate stations as inferred from the error rates detected at principal stations in the climate-day adjustment process. Errors are also possible in the precipitation data, but it is more difficult to diagnose such errors because of the very high spatial and temporal variability of precipitation. Data errors at one station can lead to higher residuals at other nearby locations. For any spatial modeling effort, close attention to data quality cannot be overemphasized.

Acknowledgments. Support for the lead author for recalculating the daily maximum and minimum temperature and precipitation to a common climate day plus the evaluation summarized in this paper was funded by Environment Canada. The authors also thank Kevin Lawrence and John Pedlar (both of the Natural Resources Canada Canadian Forest Service) for their 
efforts in this project and Eva Mekis for her helpful comments. The authors also acknowledge the helpful comments of the anonymous reviewers.

\section{REFERENCES}

Allsopp, D., 2004: History of the digital climate archive. Extended Abstracts, Workshop on Climate Data Homogenization, Toronto, Ontario, Canada, 1-11.

Hasenauer, H., K. Merganicova, R. Petritsch, S. A. Pietsch, and P. E. Thornton, 2003: Validating daily climate interpolations over complex terrain in Austria. Agric. For. Meteor., 119, 87-107.

Hutchinson, M. F., 1995: Interpolating mean rainfall using thin plate smoothing splines. Int. J. Geogr. Inf. Sci., 9, 385-403.

— cited 2010. ANUSPLIN version 4.3. Centre for Resource and Environmental Studies, Australian National University,
Canberra. [Available online at http://fennerschool.anu.edu.au/ publications/software/anusplin.php.]

, D. W. McKenney, K. Lawrence, J. H. Pedlar, R. F. Hopkinson, E. Milewska, and P. Papadopol, 2009: Development and testing of Canada-wide interpolated spatial models of daily minimum/ maximum temperature and precipitation 1961-2003. J. Appl. Meteor. Climatol., 48, 725-741.

Milewska, E., and W. D. Hogg, 2002: Continuity of climatological observations with automation. Atmos.-Ocean, 40, 333-359.

Shen, S. S. P., P. Dzikowski, G. Li, and D. Griffith, 2001: Interpolation of 1961-97 daily temperature and precipitation data onto Alberta polygons of ecodistrict and soil landscapes of Canada. J. Appl. Meteor., 40, 2162-2177.

Vincent, L. A., E. J. Milewska, R. F. Hopkinson, and L. Malone, 2009: Bias in minimum temperature introduced by a redefinition of the climatological day at the Canadian synoptic stations. J. Appl. Meteor. Climatol., 48, 2160-2168. 